Association for Information Systems

AIS Electronic Library (AISeL)

ECIS 2007 Proceedings

European Conference on Information Systems

(ECIS)

2007

\title{
The Effects of Consumer Knowledge on Message Processing of Electronic Word of Mouth via Online Consumer Reviews
}

D. Park

prehero@business.kaist.ac.kr

S. Kim

rokoiha@business.kaist.ac.kr

Ingoo Han

KAIST Business School, ighan@business.kaist.ac.kr

Follow this and additional works at: http://aisel.aisnet.org/ecis2007

\section{Recommended Citation}

Park, D.; Kim, S.; and Han, Ingoo, "The Effects of Consumer Knowledge on Message Processing of Electronic Word of Mouth via Online Consumer Reviews" (2007). ECIS 2007 Proceedings. 31.

http://aisel.aisnet.org/ecis2007/31

This material is brought to you by the European Conference on Information Systems (ECIS) at AIS Electronic Library (AISeL). It has been accepted for inclusion in ECIS 2007 Proceedings by an authorized administrator of AIS Electronic Library (AISeL). For more information, please contact elibrary@aisnet.org. 


\title{
THE EFFECTS OF CONSUMER KNOWLEDGE ON MESSAGE PROCESSING OF ELECTRONIC WORD OF MOUTH VIA ONLINE CONSUMER REVIEWS
}

\author{
Park, Do-Hyung, KAIST Business School, Seoul, South Korea, prehero@business.kaist.ac.kr \\ Kim, Sara, KAIST Business School, Seoul, South Korea, rokoiha@business.kaist.ac.kr \\ Han, Ingoo, KAIST Business School, Seoul, South Korea, ighan@business.kaist.ac.kr
}

\begin{abstract}
Today, a new form of word of mouth (WOM) called electronic word-of-mouth (eWOM) is an emerging communication channel. eWOM, unlike traditional WOM, is traceable so strategically manageable. In this paper, one type of eWOM, online consumer review, is investigated to analyze which factors influence consumer decision making. In previous research, analysis of the relationship between expertise and WOM was inconsistent. This study explains the contradiction with the cognitive fit theory by considering a moderating role of review type, one factor of the review structure. This study shows that cognitive fit occurs when experts process the reviews framed as being attribute-centric, while it occurs when novices process the reviews framed as being benefit-centric. Also, the effect of review type on purchase intention is stronger for consumers with high expertise than those with low expertise. The number of reviews, another factor of the review structure, also influences consumer information processing. This study applies the Elaboration Likelihood Model (ELM) to investigate the effect of the number of reviews. This study shows that the effect of the number of reviews on purchase intention is stronger for consumers with low expertise than those with high expertise. Our findings have implications for online sellers about how to manage online consumer reviews.
\end{abstract}

Keywords: electronic word of mouth, online consumer reviews, expertise, cognitive fit theory, Elaboration Likelihood Model

\section{INTRODUCTION}

A product progresses through a sequence of stages from introduction to growth, maturity, and decline (Day 1981). This sequence is known as the product life cycle. However, not all products go through each stage. In fact, many products fail even in the introduction phase, and the failure rate is as high as 50 percent (Cooper \& Edgett 1996). To avert this failure, marketers' marketing mix strategies should change as their products go through their individual life cycles because consumers of various stages desire different types of information (Day 1981). However, it is not easy for managers to recognize when and how they should change their way of providing product information. Moreover, since the stages are not definitely discrete, most products should appeal to consumers of different stages simultaneously. Word of mouth (WOM), which provides both attribute-value information and recommendations, is a way to help marketers overcome these limitations (Mahajan \& Muller \& Kerin 1984). However, traditionally marketers could not effectively set strategic plans about WOM because the effects of WOM were hardly traceable. Recently, the Internet emerged as a new channel of WOM (Hennig-Thurau \& Gwinner \& Walsh \& Gremler 2004). Different from traditional WOM, WOM on the Internet, called electronic word of mouth (eWOM), is measurable since comments about a product are written on the websites. Also, some types of eWOM messages such as online consumer reviews in Amazon.com are also controllable because marketers can decide whether to allow consumers' reviews 
to be shown or not. Thus, marketers can apply marketing strategies for eWOM more strategically than traditional WOM.

The eWOM information providing both product information and recommendations can satisfy various consumer segments. Consumers in the early market called early adopters want product attribute information to figure out the importance of a product with their own criteria. On the other hand, consumers in the mainstream market are relatively less knowledgeable so they prefer product benefit information (Moore 1999). They also consider peripheral cues, such as product popularity or trends, as being important. Through eWOM activity, consumers in the early market can obtain supplement product information, while consumers in the mainstream market can get user-oriented information or a signal of product popularity. Therefore, eWOM has great potential for making a product' transition from the early market to the mainstream market if it can be managed well. However, few studies have been conducted to date despite the increasing importance and popularity of online consumer review as a eWOM communication channel.

Previous research on WOM communication shows an inconsistent relationship between expertise and WOM. Some studies show a positive relationship between the level of expertise and WOM (Johson \& Russco 1984, Punj \& Staelin 1983), while other studies suggest that there is a negative relationship (Bloch \& Sherrell \& Ridgway 1986, Gilly \& Graham \& Wolfinbarger \& Yale 1998). Our study attempts to explain these contradictory results by considering the type of eWOM messages as a moderator. Consumers use different message processing strategies depending on the level of expertise. According to the cognitive fit theory (Vessey \& Galletta 1991), when the information type matches information strategy, cognitive fit occurs. Thus, the type of messages is an important factor to analyze the relationship between consumer expertise and eWOM. The study investigates which type of consumer review cognitively fits with the processing strategies depending on the level of consumer expertise. In addition, with the Elaboration Likelihood Model (ELM), the study examines for which consumers the cognitive fit is more important for decision making.

The number of reviews is another important factor of review structure. Simply, the number of reviews related to the number of previous consumers can be the signal of product popularity. Also, an increase in the number of reviews is relates to an increase in the amount of information. Thus, the number of reviews influences consumer information processing. ELM can also explain the effect of the number of reviews depending on the level of expertise. ELM posits that consumers with low expertise are more likely to focus on a peripheral cue such as the argument quantity while consumers with high expertise are more likely to engage in effortful cognitive activity through the central route and focus on the argument quality (Petty \& Cacioppo 1984).

The study proposes several hypotheses and conducts an experiment to explore how consumers process online consumer reviews with different numbers and types depending on the level of expertise. This study focuses on the overall positive reviews to clearly investigate the relationship between the review structure and consumer expertise. Negative reviews that cause other effects such as the negativity bias are not considered in this paper. Focusing our research on positive online consume reviews doesn't harm our purpose of this study because we want to know how the quality and quantity of online consumer reviews have effects on consumer purchase intention. The contributions of this research are twofold. From the theoretical perspective, the study integrates principles from different domains, which help us understand the effects of online consumer reviews. From the managerial perspective, our findings will have implications for designers of e-commerce web sites in terms of how to manage online consumer reviews. 


\section{THEORETICAL BACKGROUND \& HYPOTHESES}

\subsection{The relationship between eWOM and consumer expertise}

Prior to the Internet era, consumers shared each other's product related experiences through traditional WOM (e.g. discussions with friends and family) (Sundaram 1998). Today, the Internet makes it possible share the each other's experiences via online consumer reviews. Online consumer reviews are considered as the messages of eWOM defined as any positive or negative statement made by potential, actual, or former customers about a product, which is made available to a multitude of people and institutions via the Internet (Stauss 2000). Then, how are consumers affected by others' opinions from eWOM messages depending on the level of expertise? Previous WOM studies can not fully address this question.

Traditional WOM studies have shown contradictory results about the effect of prior knowledge on WOM behaviour. Some studies indicate prior knowledge encourages WOM behaviour because individuals with high expertise can get extra information in a faster and easier way than those with low expertise (Johson \& Russco 1984, Punj \& Staelin 1983). In contrast, some other studies show a negative relationship between the level of prior knowledge and WOM (Bloch et al. 1986, Gilly et al. 1998). Consumers with high expertise think they already have enough information to make an accurate purchase decision so they devote little effort to get product information or evaluations from others. This study suggests that the contents (type) of WOM messages is a key to resolve this inconsistent relationship. The studies on traditional WOM have not considered the message type as being important because it is not measurable. With cognitive fit theory, this paper tries to integrate prior contradictory results by considering the type of review messages as a moderator.

Cognitive fit theory indicates that individuals' information processing would be more efficient and effective when they are able to use appropriate cognitive processes from given information (Vessey \& Galletta 1991). Performance of a decision-making task will be enhanced when the information is given in a form that an individual is likely to process because the match between the information processing strategy and the information type minimizes cognitive effort (Hong \& Thong \& Tam 2004). The cognitive fit theory has been empirically validated by several studies (Agarwal \& Sinha \& Tanniru 1996, Smelcer \& Carmel 1997, Dunn \& Grabski 2001).

Individuals with different levels of expertise seek different types of information. Experts are likely to infer product benefits from product attribute information, whereas novices are likely to process expressed benefit information literally (Walker \& Celsi \& Olson 1987). That is, experts consider attribute statements as being informative, while novices find benefit statements informative (Maheswaran \& Sternthal 1990). For example, experts make judgments about food items on the basis of technical attributes (e.g. nutritional information), but novices tend to use benefit information about the items (e.g., good for you) (Walker et al. 1987).

The same review contents can be framed into two types: attribute-centric type and benefit-centric type. Reviews framed as being attribute-centric contain descriptive product information such as numbers representing attribute levels. On the other hand, in the reviews framed as being benefit-centric, interpretation of such technical attributes is presented to recommend a product.

On the basis of the cognitive fit theory, experts would engage in detailed processing of review information when it contains product attribute information. The absence of attribute information in benefit-oriented reviews inhibits experts from using their prior knowledge to evaluate the claimed benefits. However, information about physical features of a product may be meaningless to novices because they lack ability to infer all of the related benefits from a technical attribute (Alba \& Hutchinson 1987). Thus, novices consider benefit information more persuasive and useful than attribute information even though they do not show objective information about product features. For example, even when both experts and novices want to get product information from reviews about the 
same aspect of a product (e.g., If a PMP has a large memory capacity), experts seek technical attribute information from reviews (e.g., "I recommend this PMP because of its 100GB memory capacity"), while novices prefer benefit information, easy-to-understand version of such technical attribute information (e.g., "I recommend this PMP because it has a large memory capacity enough to store many photos").

Therefore, holding that a review delivers information about the same aspect of a product, the information-processing strategy of experts fits with reviews framed as being attribute-centric, while the information-processing strategy of novices fits with reviews framed as being benefit-centric. When individuals are able to process online consumer reviews represented in a cognitively fitted format, they can efficiently process given reviews, thereby those reviews positively affect purchase intention.

Hypothesis 1: The review framed as being attribute-centric fits with consumers with high expertise than the review framed as being benefit-centric type does.

Hypothesis 2: The review framed as being benefit-centric fits with consumers with low expertise than the review framed as being attribute-centric type does.

Hypothesis 3: The review framed as being attribute-centric has a stronger effect on purchase intention of consumers with high expertise than the review framed as being benefit-centric type does.

Hypothesis 4: The review framed as being benefit-centric has a stronger effect on purchase intention of consumers with low expertise than the review framed as being attribute-centric type does.

\subsection{The effect of cognitive fit (review type) and the number of reviews}

The cognitive fit theory explains which type of reviews is effective for consumers depending on the level of expertise. Then, for which consumers is the cognitive fit more important? This question can be answered from the Elaboration Likelihood Model (ELM). The ELM, a dual route theory, explains that attitude changes are based on different degrees of effortful information processing (Petty \& Cacioppo 1984). A message is transmitted and received through one of two routes of persuasion depending on the elaboration continuum: the central route and the peripheral route. In this model, the elaboration continuum refers to how motivated and able people are to assess the central merits of a stimulus. If a person has high motivation and the ability to process a message, individuals can engage in effortful cognitive activity through the central route. However, when individuals lack either the motivation or ability to process detailed information, persuasion comes from the peripheral route so they tend to rely on peripheral cues or mental heuristics rather than focal messages. Therefore, a message with many arguments can be accepted if a person thinks that "more is better," without the need to carefully evaluate those arguments (Petty \& Cacioppo 1984).

In the ELM, expertise is associated with the ability to process information. Consumers with high expertise can draw upon prior experience and knowledge to scrutinize and evaluate carefully all of the information. It is clear that such message processing demands a considerable amount of cognitive resources, but consumers with high expertise have enough cognitive resources to perform this kind of information processing. Reviews framed as being attribute-centric meet their information processing strategy. On the other hand, reviews framed as being benefit-centric do not meet their information processing because benefit-centric reviews have already been processed and interpreted by previous unknown consumers. On the other hand, consumers with low expertise lack the ability to understand and assess a product from attribute-centric product information, so they prefer the reviews framed as being benefit-centric. Even though they do not understand the reviews framed as being attributecentric well, they'll try to get a signal implying whether the reviews are positive or negative. The signal of review positiveness itself can be useful information for novices. Therefore, the impact of cognitive fit (review type) on purchase intention is stronger for consumers with high expertise than for consumers with low expertise. 
The number of reviews is another important factor of review structure. The role of the number of reviews is to provide a signal of product popularity and to increase the total amount of review information. Both roles are crucial for consumers with low expertise because they tend to rely on a peripheral cue such as the signal of product popularity, and because they are persuaded by a simple decision rule, "lots of messages are good." Consumers with high expertise are not likely to be persuaded via heuristic processing. Since experts have clear preferences for acquiring useful information for them, an increase in information quantity is welcomed only when the information fits with their needs. Thus, the effect of the number of reviews on purchase intention is stronger for consumers with low expertise than consumers with high expertise.

Hypothesis 5: The type of online consumer reviews has a stronger effect on purchase intention of consumers with high expertise than that of consumers with low expertise.

Hypothesis 6: The number of online consumer reviews has a stronger effect on purchase intention of consumers with low expertise than that of consumers with high expertise.

\section{RESEARCH DESIGN AND METHOD}

\subsection{Subjects, design and the experiment product}

222 undergraduate and graduate students participated in the experiment. All of the subjects received a gift worth $\$ 5$ for their participation. The hypotheses were tested using a 2 (levels of expertise) $\times 2$ (types of reviews) $\times 2$ (number of reviews) factorial design. The experimental procedure was the same for each group, and participants within each of the eight cells were randomly assigned. Most of the participants were familiar with online consumer reviews.

We chose a relatively new product, the Portable Multimedia Player (PMP), in order to create substantial variation in the knowledge about the product between experts and novices. The new product ensures that consumers process the suggested information with no stereotypes about the brand and its category. In addition, consumers tend to rely on the opinions from previous users due to the fact that electronic products are generally complicated. The brand name of the product was not presented in order to prevent any brand effects.

\subsection{Experimental procedure}

Subjects read the first page of the booklet, which was a statement about the study's purpose. The statement was same for all groups. Then, respondents read the product information page consisting of a product advertisement and online consumer reviews. The advertisement provided a picture of the product and a brief description of the features. Online consumer reviews were located under the advertisement. Four different sets of online consumer reviews were developed to manipulate the type and the number of reviews. Each subject was exposed to one of the two types of reviews. One type contained attribute-centric information (e.g. "I would like to recommend this PMP. One of the most attractive aspects of the PMP is that it has a large memory capacity expandable to 100GB, and it also has the display of 3.8" TFT LCD supporting (QVGA) 320x240 pixels and 262,000 colors."), while the other type contained benefit-centric information (e.g. "I would like to recommend this PMP. One of the most attractive aspects of the PMP is that it has a large memory capacity enough to store photos, and it also has a wonderful display to show photos and videos with high resolution."). The subjects encountered 3 or 8 reviews depending on their experimental conditions. The number of reviews for each condition was determined after we interviewed 20 undergraduate students in order to find out how many reviews were evaluated as being a small, or large number. Each review had 3 lines. 
After reading the product advertisement and reviews, subjects indicated their purchase intentions with two items: willing to buy/not willing to buy, willing to recommend/not willing to recommend (Cronin $\&$ Taylor 1992). In the following page, three measurement items were administered, to check the treatment effects of the review type (benefit information or attribute information). Subjects responded to three 6-point items: the reviews were informative/not informative, useful/not useful, and helpful/not helpful (Maheswaran \& Sternthal 1990). For the manipulation of the number of reviews, two items were measured to check if subjects perceived the number of reviews as we intended. Then, subject knowledge about a PMP was assessed using 12 multiple-choice questions. These questions were about the video data format, the speed of data transport, and so on. Subjective knowledge about a PMP was also measured to classify subjects as experts and novices. Since this classification had essentially the same inferences as those based on the knowledge questionnaire, the results using the self-reported measure of experience are not presented.

Finally, subjects completed measures used to control the effects of possible confounding variables in order to improve the internal validity of this study. If there is a statistically significant difference among treatment groups, these variables should be used as the covariate variables. First, the perception about review positiveness was measured. This control was measured using two items ("Reviews were positive," "Most of the reviews recommended buying the product"). Another variable was measured to control perceived quantity of consumer reviews among groups. Subjects were asked about how they felt about the quantity of given reviews through a six-point bipolar questionnaire. Finally, consumers assessed how informative the product advertisement was because the effect of seller-created information should be controlled across treatment groups.

\section{RESEARCH RESULTS}

Subjects were classified as either experts or novices according to their prior knowledge dichotomized into high and low levels. The dichotomization was based on a median split. If subjects correctly answered more than six questions, they were classified as experts. Otherwise, they were classified as novices. In this experiment, 111 subjects were experts and 111 were novices.

Since two items to measure the perceived number of reviews were loaded on a single factor (Cronbach $\alpha=0.73$ ), the average of the items was used to check whether the number of reviews was manipulated as we intended. An ANOVA analysis indicated the presence of the main effect of the number of reviews $(\mathrm{F}(1,220)=400.05, \mathrm{p}<.001)$.

Control variables including the perception of review positiveness, the perceived quantity of reviews, and the acceptance of seller-created information were analyzed to see if there were significant differences among groups. No significant difference was shown in the perception of positiveness $(\mathrm{F}(7,214)=1.90, \mathrm{~ns})$, and in the acceptance of seller-created information $(\mathrm{F}(7.214)=0.27, \mathrm{~ns})$.

To test hypotheses 1 and 2, subjects' responses relevant to the type of review information were examined. MANOVA was performed to check the effects of types of review information and levels of expertise on three dependent variables: informativeness, usefulness, and helpfulness. The results showed that there was no main effect from the type of review information (Wilks' lambda $=0.99$, ns) and expertise (Wilks' lambda $=0.99$, ns). However, there was a significant interaction effect between the type of review information and expertise (Wilks' lambda $=0.76, \mathrm{p}<0.001$ ). This interaction was significant for each dependent variables including informativeness $(F(1,218)=37.26, p<0.001)$, helpfulness $(\mathrm{F}(1,218)=53.53, \mathrm{p}<0.001)$, and usefulness $(\mathrm{F}(1,218)=62.47, \mathrm{p}<0.001)$. Planned contrasts showed the significant differences between experts and novices. For experts, attribute-centric reviews were viewed as being more informative $(F(1,218)=19.45, p<0.01)$, helpful $(F(1,218)=27.25, p<0.001)$, and useful $(\mathrm{F}(1,218)=31.14, \mathrm{p}<0.001)$ than benefit-centric reviews. By contrast, novices stated benefitcentric reviews were more informative $(F(1,218)=17.89$, $p<0.001)$, helpful $(F(1,218)=26.32, p<0.001)$, and useful $(\mathrm{F}(1,218)=31.36, \mathrm{p}<0.001)$ than attribute-centric reviews. The mean values are presented in 
Table 1. The results show that experts seek attribute information because they want to use their prior knowledge to infer product benefits from the stated attributes. Benefit information does not permit such inference. By contrast, novices prefer the benefits only messages because the specification of product benefits facilitates understanding of the given reviews. Hence, hypotheses 1 and 2 are accepted.

\begin{tabular}{ccccc}
\hline & \multicolumn{2}{c}{ Experts } & \multicolumn{2}{c}{ Novices } \\
\cline { 2 - 5 } & Attribute-centric & Benefit-centric & Attribute-centric & Benefit-centric \\
\hline Informativeness & $4.16(1.20)$ & $3.16(1.17)$ & $3.15(1.18)$ & $4.11(1.25)$ \\
Helpfulness & $4.09(1.09)$ & $2.96(1.78)$ & $2.95(1.18)$ & $4.05(1.10)$ \\
Usefulness & $3.98(0.91)$ & $2.88(1.16)$ & $2.85(1.16)$ & $3.96(0.91)$ \\
\hline
\end{tabular}

Note: Mean (Standard Deviation)

Table 1. Perceived informativeness, helpfulness, and usefulness depending on the level of expertise

Since factor analysis indicated the two items to measure product attitude were loaded on a single factor (Cronbach $\alpha=0.71$ ), the two items were averaged to compose a purchase intention score. The mean and standard deviation are in the table 2.

\begin{tabular}{ccccc}
\hline & \multicolumn{2}{c}{ Experts } & \multicolumn{2}{c}{ Novices } \\
\cline { 2 - 5 } & Attribute-centric & Benefit-centric & Attribute-centric & Benefit-centric \\
\hline Small number of & $3.33(0.57)$ & $2.54(0.54)$ & $2.72(0.54)$ & $2.98(0.46)$ \\
reviews & $\mathrm{n}=27$ & $\mathrm{n}=28$ & $\mathrm{n}=27$ & $\mathrm{n}=28$ \\
large number of & $4.18(0.70)$ & $2.80(0.52)$ & $3.86(0.69)$ & $4.38(1.00)$ \\
reviews & $\mathrm{n}=28$ & $\mathrm{n}=28$ & $\mathrm{n}=28$ & $\mathrm{n}=28$ \\
\hline
\end{tabular}

Table 2. Descriptive statistics of purchase intention

To test hypotheses 3, 4, 5 and 6, an ANOVA was performed. The two way interaction effect between review type and expertise was revealed $(\mathrm{F}(1,214)=71.87, \mathrm{p}<0.001)$. The relationship is shown in the figure 1. For experts, the purchase intention is higher when they are given attribute-centric reviews than benefit-centric reviews $(F(1,218)=49.73, p<0.01)$. By contrast, the purchase intention of novices is higher when they are given benefit-centric reviews than attribute-centric reviews $(F(1,218)=5.95$, $\mathrm{p}<0.015$ ). The results are consistent with the expectation based on the cognitive fit theory that experts have higher purchase intention when they read attribute-centric reviews, while novices have higher purchase intention attitude when they are exposed to benefit-centric reviews. Thus, hypotheses 3 and 4 are supported. In addition, a planned contrast revealed that the differences of purchase intention scores between benefit-centric reviews and attribute-centric reviews is greater for experts than novices $(\mathrm{F}(1,218)=10.63, \mathrm{p}<0.001)$. Thus, hypothesis 5 is accepted. To test hypothesis 4 , the two way interaction effect between the number of reviews and expertise was revealed $(F(1,214)=16.52$, $\mathrm{p}<0.001)$. The relationship is shown in the figure 2 . The increase in purchase intention of novices from the small number of reviews to the large number of reviews is greater than the increase in purchase intention of experts $(\mathrm{F}(1,218)=11.34, \mathrm{p}<0.001)$. Thus, hypothesis 6 is also accepted. 


\begin{tabular}{ccc}
\hline & \multicolumn{2}{c}{ Purchase Intention } \\
\cline { 2 - 3 } & F-value & p-value \\
\hline Number of Reviews & 109.441 & .001 \\
Type of Reviews & 16.063 & .001 \\
Expertise & 9.725 & .002 \\
Number of Reviews $\times$ Type of Reviews & 0.842 & .360 \\
Number of Reviews $\times$ Expertise & 16.523 & .001 \\
Type of Reviews $\times$ Expertise & 71.867 & .001 \\
Number of Reviews $\times$ Type of Reviews $\times$ Expertise & 5.761 & .017 \\
\hline
\end{tabular}

Table 3. ANOVA results

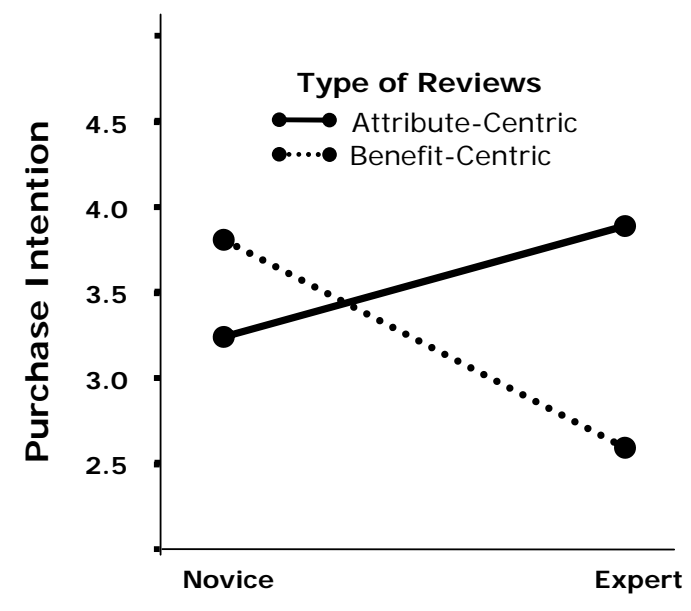

The Level of Expertise

Figure 1. The interaction effect of the level of expertise $\times$ the type of reviews

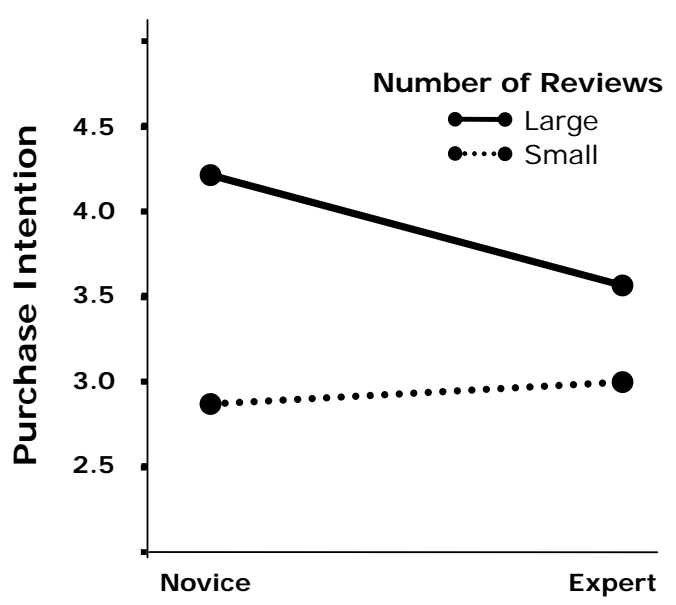

The Level of Expertise

Figure 2. The interaction effect of the level of expertise $\times$ the number of reviews 


\section{CONCLUSION}

This study has several theoretical contributions. First, this study provides a potential explanation for the inconsistent analysis of the relationship between WOM and expertise by considering the type of WOM messages as a moderator. Studies on traditional WOM have not investigated the moderating role of message type because it was difficult to measure and trace the contents of WOM messages. This study focusing on online consumer reviews as eWOM messages explains the contradiction with the cognitive fit theory. Cognitive fit occurs when experts process the reviews framed as being attribute-centric, while it occurs when novices process the reviews framed as being benefit-centric.

Second, this study applies the ELM to investigate the effects of cognitive fit (review type) and the number of reviews. By integrating cognitive fit theory and ELM, the study examines that consumers with different levels of expertise prefer different types of review messages (based on cognitive fit theory), and the effect of cognitive fit on purchase intention is stronger for experts than for novices (based on ELM). It results from that experts have clear preferences of review information. On the other hand, the number of reviews is a more important factor for novices than for experts. It is because the number of reviews can be a peripheral cue to show product popularity and many advantages of products for novices.

The findings of this study have several managerial implications. The present findings help marketers to develop strategic plans along with the product life cycle. Marketers need to provide differently framed product information for potential consumers with different levels of expertise. In the introduction stage of a product, target consumers have relatively high level of product knowledge, so reviews should contain attribute information. On the other hand, consumers in the main stream market (consumers in the maturity stage of the product life cycle) have relatively low level of product knowledge, so they seek reviews framed being as benefit-centric. Online sellers can deliver product information framed in a cognitively fitted way for both experts and novices by providing a standardized review format for previous users who want to post their opinions about a product. It is important for online sellers to guide review posters to write about the same aspect of a product in two different frames: attribute-centric and benefit centric frames. In an attribute-centric frame, technical and specific attribute information to support their recommendations should be presented. On the other hand, in a benefit-centric frame, benefits from such technical attributes should be literally explained. The study also shows that consumers with relatively low level of expertise make their purchasing decision based on a simple decision rule. Therefore, online sellers can provide them with peripheral cues such as the number of reviews without having them count the number of reviews by themselves. Online sellers also facilitate the understanding of reviews for novices using the star system. When a review has many stars, potential consumers with low experts can simply infer the review is well written.

There are some limitations to this study. First, we limit our investigation to positive reviews. However, in reality, consumers also read the negative reviews that suggest not purchasing the product. Future research might extend the present research by addressing the effects of negative eWOM on consumer behaviour. Second, according to ELM, product involvement is also a critical factor that affects the perception of online consumer reviews because consumers relatively more rely on consumer reviews when they want to purchase high involvement products such as expensive products. However, in the study, involvement is controlled through random assignment of subjects. Finally, product category (for example, high-tech vs. low-tech) and product type (tangible vs. intangible) may also have an effect on information processing of online consumer reviews. The effects of online consumer reviews can be generalized in further studies by considering these variables. 


\section{References}

Agarwal, R., Sinha, A.P. and Tanniru, M. (1996). Cognitive fit in requirement modeling: a study of object and process methodologies. Journal of Management Information Systems, 13 (2), 137-163.

Alba, J.W. and Hutchinson, J.W. (2002) Dimensions of consumer expertise. Journal of Consumer Research, 13 (4), 411-454.

Bloch, P.H., Sherrell, D.L. and Ridgway, N.M. (1986). Consumer search: an extended framework. Journal of Consumer Research, 13 (1), 119-126.

Cooper, R.G. and Edgett, S.J. (1996). Critical success factors for new financial services. Marketing Management, 5 (4), 26-37.

Cooper, R.G. (1979). The dimensions of industrial new product success and failure. Journal of Marketing, 43 (3), 93-103.

Cronin Jr.J.J. and Taylor, S.A. (1992). Measuring service quality: a reexamination and extension. Journal of Marketing, 56 (3), 55-68.

Day, G.S. (1981). The product life cycle: analysis and applications issues. Journal of Marketing, 45 (4), 60-67.

Dunn, C. and Grabski, S. (2001). An investigation of localization as an element of cognitive fit in accounting model representations. Decision Sciences, 32 (1), 55-94.

Gilly, M.C., Graham, J.L., Wolfinbarger, M.F. and Yale, L.J. (1998). A dyadic study of interpersonal information search. Journal of the Academy of Marketing Science, 26 (2), 83-100.

Hennig-Thurau, T., Gwinner, K.P., Walsh, G, and Gremler, D.D. (2004). Electronic word-of-mouth via consumer opinion platforms: what motivates consumers to articulate themselves on the internet? Journal of Interactive Marketing, 18 (1), 38-52.

Hong, W., Thong, J.Y.L. and Tam, K.Y. (2004). The effects of information format and shopping task on consumers' online shopping behavior: a cognitive fit perspective. Journal of Management Information Systems, 21 (3), 149-184.

Keller, K.L. and Staellin, R. (1987). Effects of quality and quantity of information on decision effectiveness. Journal of Consumer Research, 14 (2), 200-13.

Mahajan, V., Muller, E. and Kerin, R.A. (1984). Introduction strategy for new products with positive and negative word-of-mouth. Management Science, 30 (12), 1389-1404.

Maheswaran, D. and Sternthal, B. (1990). The effects of knowledge, motivation, and type of message on ad processing and product judgments. Journal of Consumer Research, 17 (1), 66-73.

Malhotra, N.K. (1984). Reflections on the information overload paradigm in consumer decision making. Journal of Consumer Research, 10 (4), 436-437.

Moore, G.A. (1999). Crossing the Chasm: Marketing and selling High Tech Products to Mainstream Customers, Harper Collins Publishers, New York.

Petty, R.E. and Cacioppo, J.T. (1984). The effects of involvement on response to argument quantity and quality: central and peripheral routes to persuasion. Journal of Personality and Social Psychology, 46 (1), 69-81.

Punj, G.N. and Staelin, R. (1983). A model of consumer information search behavior for new automobiles. Journal of Consumer Research, 9 (4), 366-380.

Smelcer, J.B. and Carmel, E. (1997). The effectiveness of different representations for managerial problem solving: comparing tables and maps. Decision Sciences, 28 (2), 391-421.

Stauss B. (2000) Using new media for customer interaction: a challenge for relationship marketing. in Henning-Thurau, T. and U. Hansen (Eds.), Relationship Marketing, Springer, Berlin.

Sundaram, D.S., Mitra, K. and Webster, C. (1998) Word-of- mouth communications: a motivational analysis. Association for Consumer Research, 25, 527-31.

Vessey, I. and Galletts, D. (1991). Cognitive fit: an empirical study of information acquisition. Information Systems Research, 2 (1), 63-84.

Walker, B., Celsi, R. and Olson, J. (1987) Exploring the structural characteristics of consumers' knowledge. Advances in Consumer Research, 14, 17-21. 